\title{
ЭФФЕКТИВНОСТЬ СРЕДНЕСРОЧНОГО ПЛАНИРОВАНИЯ ФЕДЕРАЛЬНЫХ РАСХОДОВ В ГЕРМАНИИ: ТОЧНОСТЬ БЮДЖЕТНЫХ ПРОЕКТИРОВОК
}

\begin{abstract}
Аннотация. В статье рассмотрена эффективность среднесрочного финансового планирования в Германии с точки зрения точности реализации бюджетных проектировок по федеральным расходам. Использованы данные о формировании и исполнении трёх пятилетних планов (на 2002-2006 г2., 2007-2011 г2., 2012-2016 г2.). В иелях укрупнения и стандартизации статей функииональной классификачии расходов, применяемой в федеральных финансовых планах Германии, автор провёл трансформацию этих статей в раздель функциональной классификации расходов, установленной Международным валютным фондом. Эта трансформация позволила оченить точность финансового планирования расходов по международной методологии РЕFА. Сопоставление финансовых планов с их исполнением было проведено в четырёх разрезах (совокупные расходы по функциональной классификации, совокупные расходы по экономической классификации, текущие расходы по функииональной классификации, капитальные расходы по функциональной классификации). Результаты расчетов позволили сделать вывод о том, что при переходе от первой пятилетки ко второй и далее к третьей отклонения фактических расходов от запланированных последовательно уменьшались - как в целом, так и по обеим классификациям (функциональной и экономической) и в обоих измерениях (абсолютном и относительном). Это свидетельствует о целенаправленном повышении точности планирования бюджетных расходов в Германии, опирающемся на новые технологии составления бюджета, применение которых было бы весьма полезно в России.
\end{abstract}

Ключевые слова: пятилетнее финансовое планирование в Германии, расходы федерального бюджета, функциональная классификация, экономическая классификаџия, текущие расходы, капитальные расходы.

Среднесрочное (пятилетнее) финансовое планирование - важная составная часть государственной экономической политики Германии. С 1967 г. оно является обязательным для федерального бюджета. Нормативно-правовую основу среднесрочного финансового планирования составляют Закон о содействии стабильности и росту экономики 1967 г. $(\S \S 9,10)$ и Закон о бюджетных принципах 1969 г. (§§ 50, 51, 52). Пятилетний финансовый план ежегодно составляется Министерством финансов Германии. Правительство утверждает этот объёмный документ в конце июня - начале июля и представляет его в Парламент в августе. Первым годом пятилетки является текущий год (его бюджет утверждался Парламентом в виде закона в предыдущем году), вторым - следующий год (его бюджет вносится в Парламент в сентябре и

\footnotetext{
(C) Грачева Мария Владимировна - кандидат экономических наук, ведущий научный сотрудник Национального исследовательского Института мировой экономики и международных отношений им. Е.M. Примакова РАН. Aдpec: 117997, Россия, Москва, ул. Профсоюзная, д. 23. E-mail: mgracheva@mail.ru. SPIN-код РИНЦ: 4779-8130.
}

DOI: http://dx.doi.org/10.15211/vestnikieran620183 
утверждается Парламентом в виде закона не позднее декабря текущего года). Бюджетные проектировки на третий, четвёртый и пятый годы пятилетки в виде закона не утверждаются, они представляются в Парламент в качестве информации.

Пятилетний финансовый план является скользящим:

• ежегодно первый, истекший год предыдущей пятилетки убирается;

• второй год предыдущей пятилетки становится первым годом новой пятилетки, его бюджет является законом, утверждённым в истекшем году;

- третий год предыдущей пятилетки становится вторым годом новой пятилетки, его бюджет корректируется и утверждается в виде закона в первом году новой пятилетки;

• четвёртый и пятый годы предыдущей пятилетки становятся третьим и четвёртыми годами новой пятилетки, их бюджетные проектировки корректируются;

- добавляются бюджетные проектировки на ещё один, пятый год новой пятилетки.

В конце 1960-х и в 1970-е гг., в связи с введением среднесрочного финансового планирования в практику государственного регулирования, в Германии наблюдался настоящий исследовательский бум в отношении данного инструмента. Появилось множество публикаций, посвящённых его концептуальным основам ${ }^{1}$, месту в системе государственного управления ${ }^{2}$,

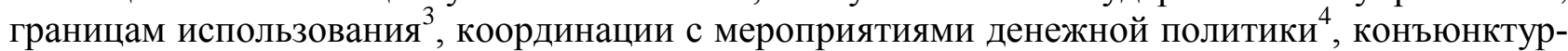
ной политики ${ }^{5}$, макрофинансовой политики ${ }^{6}$, макроэкономической политики ${ }^{7}$. Анализировались проблемы обеспечения согласованности с процессами развития бюджетирования ${ }^{8}$, бюджетного права ${ }^{9}$, бюджетного федерализма ${ }^{10}$.

Затем упор в исследовании этой темы был сделан на проблемах соотнесения среднесрочных финансовых планов с другими государственными плановыми инструментами ${ }^{11}$, с подготовкой федеральных годовых бюджетов ${ }^{12}$, а также с необходимостью соблюдения жёстких финансовых ограничений ${ }^{13}$ и принципов современного демократического государства ${ }^{14}$.

В 2010-е гг. внимание к пятилетнему финансовому планированию вновь усиливается: продолжается анализ его взаимосвязи с бюджетированием ${ }^{15}$ и с системой госфинансов в целом $^{16}$. Начинает использоваться новый важный подход - исследование планирования государственных расходов с точки зрения теории поведенческой экономики ${ }^{17}$.

Целью данного исследования является анализ эффективности среднесрочного финансового планирования в Германии, а именно рассмотрение особенностей динамики и структуры расходов федерального бюджета страны через призму формирования и исполнения четырёх пятилетних финансовых планов (на 2002-2006 гг., 2007-2011 гг., 2012-2016 гг., 20172021 гг.). Эффективность планирования расходов определяется с двух сторон - точности

\footnotetext{
${ }^{1}$ Fahning, 1967; Gresser, 1974; Grund, 1968.

2 Waterkamp, 1978; Zavelberg, 1970.

${ }^{3}$ Schmidt, Wille, 1970.

4 Albers, 1968.

${ }_{6}^{5}$ Haller, 1968; Neumark, 1968.

${ }^{6}$ Neumark, 1969; Schmölders, 1970.

${ }^{7}$ Hansmeyer, 1972; Körner, 1967.

${ }^{8}$ Zabel, 1971; Zunker, 1972.

${ }^{9}$ Fischer-Menshausen, 1969.

${ }^{10}$ Hagemann, 1968.

${ }_{11}^{11}$ Rürup, Hansmeyer, 1984.

12 Vierling, 2008.

${ }^{13}$ Schwarzner, 1991.

${ }_{14}$ Blankart, 2003

15 Pfäffli, 2011; Seiwald et al., 2013.

${ }_{16}^{16}$ Corneo, 2012; Leibinger et al, 2017.

${ }^{17}$ Döring, 2016.
} 
реализации бюджетных проектировок и сущности осуществленных/намечаемых структурных сдвигов в расходной части бюджета. В предлагаемой статье рассматривается первый из указанных аспектов.

Для оценки точности бюджетных проектировок необходимо решить следующие задачи:

- трансформировать статьи функциональной классификации, применяемой в федеральных финансовых планах Германии, в разделы функциональной классификации Международного валютного фонда (МВФ);

- сопоставить финансовые планы на 2002-2006 гг., 2007-2011 гг., 2012-2016 гг. с их исполнением, причём провести это сравнение факт/план в четырёх разрезах: совокупные расходы по функциональной классификации МВФ, совокупные расходы по экономической классификации, текущие расходы по функциональной классификации МВФ, капитальные расходы по функциональной классификации МВФ.

\section{Трансформация статей функциональной классификации}

Функциональная классификация федерального пятилетнего финансового плана была укрупнена и приведена к международному стандарту в виде функциональной классификации Международного валютного фонда ${ }^{1}$ (см. Приложение, табл. 1). Трансформация была проведена в целях оценки точности планирования федеральных расходов в Германии по функциональной классификации согласно требованиям индикатора PI-2.1 в рамках методологии PEFA (Public Expenditure and Financial Accountability), применяемой Международным валютным фондом и Всемирным банком².

В результате проведённой трансформации статьи функциональной классификации, применяемой в федеральных финансовых планах Германии, были сгруппированы в разделы функциональной классификации МВФ (см. Приложение, табл. 2).

После трансформации единственным отклонением от функциональной классификации МВФ является включение расходов на науку в раздел «Образование». Устранить это отличие не представляется возможным, поскольку в федеральных финансовых планах Германии расходы на науку отражаются в одной статье целиком и не разбиваются по разделам функциональной классификации.

Экономическая классификация расходов, применяемая в финансовых планах Германии, в целом соответствует экономической классификации $\mathrm{MB}^{3}$ и не требует трансформации для оценки точности планирования федеральных расходов по указанной классификации согласно требованиям индикатора PI-2.2 в рамках методологии PEFA ${ }^{4}$.

\section{Финансовые планы в 2002-2016 гг. и их исполнение}

Сопоставление плановых пятилеток на 2002-2006 гг., 2007-2011 гг. и 2012-2016 гг. с их реализацией было проведено следующим образом. Объёмы запланированных расходов рассчитаны по проектировкам трёх пятилетних федеральных финансовых планов, опубликованных в 2002 г., 2007 г. и 2012 г. Объёмы фактических расходов рассчитаны по исполненным годовым федеральным бюджетам, опубликованным в 15 федеральных финансовых планах в 2003-2017 гг. ${ }^{5}$ В соответствии со схемой, указанной в табл. 2, объёмы расходов по разделам германской функциональной классификации трансформированы в объёмы по раз-

\footnotetext{
${ }^{1}$ Government Finance Statistics Manual 2014, 2014. P. 143.

${ }_{3}^{2}$ PEFA. Framework for assessing public financial management 2016. 2016. P. 15.

${ }^{3}$ Government Finance Statistics Manual 2014. 2014. P. 116.

${ }_{5}^{4}$ PEFA. Framework for assessing public financial management 2016. 2016. P. 15.

5 Источник данных о пятилетних финансовых планах Германии: http://pdok.bundestag.de/
} Научно-аналитический вестник ИЕ РАН, 2018, №6 
делам функциональной классификации МВФ.

Результаты расчётов, показывающих соотношение факт/план по функциональной классификации (ФК), представлены в табл. 3 Приложения, по экономической классификации (ЭК) - в табл. 4 Приложения.

Сравнение финансовых планов с их исполнением свидетельствует:

* в 2002-2006 гг. отклонение фактических расходов от запланированных составило +44,7 млрд евро, т.е. 3,6\% плана совокупных расходов, в т.ч.:

$>\quad$ в части расходов, распределённых по ФК, положительное отклонение составило 44,3 млрд евро, т.е. 3,6\% плана,

$>\quad$ в части расходов, распределённых по ЭК, положительное отклонение составило 33,8 млрд евро, т.е. 2,7\% плана;

* в 2007-2011 гг. отклонение фактических расходов от запланированных составило $+27,5$ млрд евро, т.е. $1,9 \%$ плана совокупных расходов, в т.ч.:

$>\quad$ в части расходов, распределённых по ФК, положительное отклонение составило 18,9 млрд евро, т.е. 1,3\% плана,

$>$ в части расходов, распределённых по ЭК, положительное отклонение составило 27,4 млрд евро, т.е. 1,9\% плана;

* в 2012-2016 гг. отклонение фактических расходов от запланированных составило $+7,6$ млрд евро, т.е. 0,5\% плана совокупных расходов, в т.ч.:

$>\quad$ в части расходов, распределённых по ФК, отклонение оказалось отрицательным и составило 6,1 млрд евро, т.е. 0,4\% плана,

$>\quad$ в части расходов, распределённых по ЭК, отклонение также оказалось отрицательным и составило 16,0 млрд евро, т.е. 1,0\% плана.

Данные о распределении отклонений расходов по ФК и ЭК позволяют выявить главные факторы несовпадения фактов с планами. Максимальные отклонения имели место:

• в 2002-2006 гг.: по ФК - в социальной защите (+4,8\% плана совокупных расходов), по ЭК - в текущих субсидиях/дотациях $(+4,8 \%)$;

• в 2007-2011 гг.: по ФК - в здравоохранении (+ 3,0\% плана совокупных расходов), по ЭК - в текущих субсидиях/дотациях $(+3,1 \%)$;

•в 2012-2016 гг.: по ФК - в госслужбах общего назначения (-2,1\% плана совокупных расходов), по ЭК - в текущих расходах на выплату процентов по госдолгу $(-3,4 \%)$.

Во всех трёх пятилетках основным фактором отклонений стали текущие расходы. Их распределение по ФК представлено в табл. 5 Приложения, эти данные подтверждают: перерасходы в первой и второй пятилетках были обусловлены прежде всего соцзащитой и здравоохранением соответственно (а именно, выплатами в связи с безработицей в 2002-2006 гг. и финансированием Фонда обязательного медицинского страхования в 2007-2011 гг.); экономия в третьей пятилетке была достигнута за счёт сокращения расходов на госслужбы общего назначения (а именно, на проценты по госдолгу).

Размеры максимальных отклонений факта от плана сократились с $+58,1$ млрд евро $(+5,4 \%$ плана текущих расходов) в 2002-2006 гг. до $+43,7$ млрд евро $(+3,4 \%$ плана текущих расходов) в 2007-2011 гг. и до -33,4 млрд евро (-2,4\% плана текущих расходов) в 2012-2016 гг.

Что касается капитальных расходов, то их распределение по ФК представлено в табл. 6 Приложения. Оно показывает, что ключевыми факторами отклонений факта от плана в 20022006 гг. и в 2007-2011 гг. стали расходы на экономику, причём эти отклонения оказались разнонаправленными и почти одинаковыми по суммам. В первой пятилетке имела место экономия на 8,1 млрд евро, или 6,3\% плана капитальных расходов (в основном за счёт госгарантий 
и инфокоммуникационных технологий), во второй пятилетке - перерасход на 9,3 млрд евро, или 7,6\% плана капитальных расходов (главным образом за счёт транспортной сети). В третьей же пятилетке максимальное отклонение факта от плана оказалось гораздо скромнее, им стал перерасход в сфере образования/науки на сумму 4,5 млрд евро, или 3,0\% плана капитальных расходов.

\section{Выводы}

Проведённые расчёты позволяют сделать следующие выводы. Во-первых, представляется возможным разделить разделы/статьи ФК/ЭК на группы с пониженной и повышенной точностью бюджетных проектировок (у которых отклонения факт/план превышали/не превышали 2\% плана совокупных расходов). К менее точным сферам планирования относятся: по ФК - социальная защита, здравоохранение, образование/наука (перерасход), государственные службы общего назначения (экономия), экономические вопросы (как перерасход, так и экономия); по ЭК - текущие субсидии/дотации (перерасход) и проценты по госдолгу (экономия). К более точным сферам планирования относятся: по ФК - оборона, общественный порядок/безопасность, охрана окружающей среды, жилищная/коммунальная инфраструктура, отдых/ культура/религия; по ЭК - текущие расходы на персонал и госзакупки, а также капитальные расходы.

Во-вторых, на протяжении трёх рассмотренных пятилеток точность финансового планирования в Германии по методологии PEFA оценивается как наивысшая, а именно на уровне A: отклонения факта от плана не превышают 5\% как по федеральным расходам в целом (индикатор PI-1.1), так и в разрезах основных разделов/статей ФК/ЭК (индикаторы PI-2.1 и PI2.2). При этом результаты расчётов ясно показывают, что при переходе от первой пятилетки ко второй и далее к третьей отклонения фактических расходов от запланированных последовательно уменьшались - как в целом, так и по обеим классификациям и в обоих измерениях (абсолютном и относительном).

Чёткая тенденция повышения точности финансового планирования в Германии опирается во многом на применение новых технологий подготовки бюджета, и этот опыт мог бы оказаться весьма полезным для сферы госфинансов России. В условиях снизившихся темпов роста российской экономики особенно эффективным могло бы стать внедрение таких передовых бюджетных процессов, как процедура анализа бюджетных расходов ${ }^{1}$ и создание независимого бюджетного института ${ }^{2}$.

\section{Список литературы}

Германия. 2017. Глава 5 «Новые технологии формулирования федерального бюджета Германии: создание независимого бюджетного института». Доклады Института Европы РАН № 354. Под ред. В.Б. Белова. М., 2018.

Источник данных о пятилетних финансовых планах Германии (2002-2006, 2003-2007, 2004-2008, 2005-2009, 2006-2010, 2007-2011, 2008-2012, 2009-2013, 2010-2014, 2011-2015, 2012-2016, 2013-2017, 2014-2018, 2015-2019, 2016-2020, 2017-2021): http://pdok.bundestag. de/ (дата обращения: 17.09.2018).

\section{References}

Germany. 2017. Chapter 5 «New Technologies in Drafting the German Federal Budget: Creat-

\footnotetext{
${ }_{1}^{1}$ Spending review - Government at a glance, 2017; Spending reviews im Bundeshaushalt, 2016.

2 Германия. 2017. С. 54-64.
}

Научно-аналитический вестник ИЕ РАН, 2018, №6 
ing an Independent Budgetary Institution». Reports of the Institute of Europe №354. Moscow, 2018.

Albers W. Einige Fragen zur mittelfristigen Finanzplanung // Geldtheorie und Geldpolitik. Günter Schmölders zum 65. Geburtstag / C.A. Andreae, K.-H. Hansmeyer, G. Scherhorn (Hrsg.). Berlin: Duncker \& Humblot, 1968.

Blankart C. Öffentliche Finanzen in der Demokratie. München: Franz Vahlen, 2003.

Corneo G. Öffentliche Finanzen: Ausgabenpolitik. Tübingen: Mohr Siebeck, 2012.

Döring T. Staatliche Ausgabenpolitik verhaltensökonomisch betrachtet - Zur Psychologie der öffentlichen Ausgabentätigkeit // List Forum für Wirtschafts- und Finanzpolitik. 2016. Bd. 1.

Fahning H. Probleme der mittelfristigen Finanzplanung // Wirtschaftsdienst. 1967. H. III.

Fischer-Menshausen H. Mittelfristige Finanzplanung und Haushaltsrecht // Schriften des Vereins für Socialpolitik. 1969. Bd. 52.

Government Finance Statistics Manual 2014. Washington, D.C.: International Monetary Fund, 2014.

Gresser K. Probleme der mehrjährigen öffentlichen Finanzplanung // Volkswirtschaftliche Schriften. 1974. H. 211.

Grund W. Die mehrjährige Finanzplanung des Bundes. Grundkonzeption, Methoden und ihre Problematik // Planung III. Mittel und Methoden planender Verwaltung / J.C. Kaiser (Hrsg.). Baden-Baden: Nomos Verlagsgesellschaft, 1968.

Hagemann G. Beziehungen zwischen mittelfristiger Finanzplanung und Finanzverfassung im föderativen Staat unter besonderer Berücksichtigung der Verhältnisse in der BRD // Beihefte der Konjunkturpolitik.1968. H. 15.

Haller H. Probleme der mittelfristigen Finanzplanung // Konjunkturpolitik: Zeitschrift für angewandte Konjunkturforschung. 1968. Jg. 14.

Hansmeyer K.-H. Die mittelfristige Finanzplanung - ein neues Instrument der Wirtschaftspolitik? // Schriften des Vereins für Socialpolitik. 1972. Bd. 67.

Körner H. Wirtschaftspolitische Aspekte der mittelfristigen Finanzplanung // Wirtschaftsdienst. 1967. H. X.

Leibinger B., Müller R., Wiesner H. Öffentliche Finanzwirtschaft. Heidelberg: R. v. Decker, 2017.

Neumark F. Mittelfristige Finanzplanung // Beihefte der Konjunkturpolitik.1968. H. 15.

Neumark F. Planung in der öffentlichen Finanzwirtschaft // Finanzpolitik / H.C. Recktenwald (Hrsg.). Köln, Berlin: Kiepenheuer \& Witsch, 1969.

PEFA. Framework for assessing public financial management 2016. Washington, D.C.: PEFA Secretariat, 2016.

Pfäffli S. Budgetierung im öffentlichen Sektor. Ein Handbuch für Studium und Praxis aus finanzwissenschaftlicher Sicht. Bern, Stuttgart, Wien: Haupt Verlag, 2011.

Rürup B., Hansmeyer K.-H. Staatswirtschaftliche Planungsinstrumente. Düsseldorf: Werner Verlag, 1984.

Schmidt K., Wille E. Die mehrjährige Finanzplanung - Wunsch und Wirklichkeit // Wirtschaft und Gesellschaft. 1970. Bd. 3.

Schmölders G. Die Ausgabenpolitik / Finanzpolitik. Kapitel IV. Berlin: Springer-Verlag, 1970.

Schwarzner G. Öffentliche Haushalts- und Finanzplanung bei Finanzierungsengpässen : ein Beitrag zur finanzwirtschaftlichen Ordnungspolitik. // Schriften zur wirtschaftswissenschaftlichen Analyse des Rechts. 1991. Bd. 8.

Seiwald J., Meyer R., Hammerschmid G., Egger-Peitler I., Höllerer M.A. Budgetplanung als 
Zusammenspiel von Regeln, Instrumenten und Praktiken / Neue Wege des Haushaltsmanagements. Internationale Erfahrungen, Herausforderungen und Trends. Berlin: edition sigma, 2013.

Spending review. In: Government at a glance 2017. Paris: OECD Publishing, 2017.

Spending reviews im Bundeshaushalt // Monatsbericht des BMF. 2016. No 9. S. 14-21.

Vierling M. Mittelfristige Finanzplanung und jährliche Haushaltsplanung des Bundes // Wirtschaftsdienst. 2008. H. 1.

Waterkamp R. Finanzplanung / Handbuch politische Planung. Opladen: Leske Verlag + Budrich $\mathrm{GmbH}, 1978$.

Zabel G. Mittelfristige Finanzplanung // Das rationale Budget / K.-H. Hansmeyer (Hrsg.). Köln: Kölner Universitätsverlag, 1971.

Zavelberg H-G. Die mehrjährige Finanzplanung — ein notwendiges Instrument moderner Politik // Die Verwaltung: Zeitschrift für Verwaltungswissenschaft. 1970. Bd. 3.

Zunker A. Finanzplanung und Bundeshaushalt. Zur Koordinierung und Kontrolle durch den Bundesfinanzminister // Planungsstudien. 1972. Bd. 9.

Data source on five-year financial plans in Germany (2002-2006, 2003-2007, 2004-2008, 2005-2009, 2006-2010, 2007-2011, 2008-2012, 2009-2013, 2010-2014, 2011-2015, 2012-2016, 2013-2017, 2014-2018, 2015-2019, 2016-2020, 2017-2021): http://pdok.bundestag.de/ (last accessed date: 17.09.2018).

\section{Efficiency of the medium-term planning of federal expenditures in Germany: accuracy of budgetary projections}

Author. Maria Gracheva, Candidate of Sciences (Economics), Leading Research Associate, Primakov National Research Institute of World Economy and International Relations, Russian Academy of Sciences. Address: 23, Profsoyuznaya str., Moscow, Russia, 117997. E-mail: mgracheva@mail.ru.

Abstract. The article examines the efficiency of medium-term financial planning in Germany from the point of view of the accuracy of budget projections for federal expenses. The author used the data on the formation and execution of three five-year plans (for 2002-2006, 2007-2011, 20122016). In order to consolidate and standardize the items of the functional classification of expenses used in Germany's federal financial plans, the author has transformed these items into the divisions of the functional classification of expenses established by the International Monetary Fund. This transformation allowed to estimate the accuracy of German financial planning according to the PEFA methodology. The comparison of financial plans with their execution was carried out in four profiles (total expenses by functional classification, total expenses by economic classification, current expenses by functional classification, capital expenses by functional classification). The results of calculations led to the conclusion that with the transition from the first of the abovementioned five-year plans to the second one and, further, to the third one, the deviations of the actual expenses from the planned ones reduced consistently: in total volumes, in both classifications (functional and economic), in both dimensions (absolute and relative). This indicates a deliberate increase in the accuracy of the budget expenditures' planning in Germany on the base of new budget technologies.

Key words: five-year financial planning in Germany, federal budget's expenses, functional classification, economic classification, current expenses, capital expenses.

DOI: http://dx.doi.org/10.15211/vestnikieran620183 
ПРИЛОЖЕНИЕ

Таблица 1

Трансформация статей функциональной классификации, применяемой

в федеральных финансовых планах Германии, в разделы функциональной

классификации Международного валютного фонда (МВФ)

\begin{tabular}{|c|c|c|c|}
\hline \multicolumn{2}{|c|}{$\begin{array}{c}\text { Статьи функциональной классификации, применяемой в } \\
\text { федеральных финансовых планах Германии }\end{array}$} & \multirow[t]{3}{*}{\begin{tabular}{|c|} 
Направление \\
трансформации
\end{tabular}} & \multirow[t]{2}{*}{\begin{tabular}{|c|}
$\begin{array}{c}\text { Разделы функциональной } \\
\text { классификации МВФ }\end{array}$ \\
\end{tabular}} \\
\hline $\begin{array}{l}\text { A. (2002-2003) } \\
\text { Социальная защита } \\
\text { 3.2.1 (2004-2017) } \\
\end{array}$ & & & \\
\hline \begin{tabular}{|l|} 
A.1 (2002-2003) \\
3.2.1.1 (2004-2017)
\end{tabular} & $\begin{array}{l}\text { Федеральный фонд обязательного } \\
\text { пенсионного страхования }\end{array}$ & & 710. Социальная защита (пенсии) \\
\hline $\begin{array}{l}\text { A.2 (2002-2003) } \\
\text { 3.2.1.2 (2004-2017) }\end{array}$ & $\begin{array}{l}\text { Политика на рынке труда (содей- } \\
\text { ствие трудоустройству, базовое } \\
\text { обеспечение безработных) }\end{array}$ & & $\begin{array}{l}\text { 710. Социальная защита (безра- } \\
\text { ботица) }\end{array}$ \\
\hline \begin{tabular}{|l|} 
A.3 (2002-2003) \\
3.2.1.2(2004-2017) \\
\end{tabular} & $\begin{array}{l}\text { Семейная политика (поддержка } \\
\text { родителей и детей) }\end{array}$ & & $\begin{array}{l}\text { 710. Социальная защита (семья и } \\
\text { дети) }\end{array}$ \\
\hline \begin{tabular}{l|}
$\mathrm{A}, 4(2002-2003)$ \\
3.2.1.4 (2004-2017) \\
\end{tabular} & $\begin{array}{l}\text { Льготная аренда жилья для мало- } \\
\text { имущих }\end{array}$ & & 710. Социальная защита (жилье) \\
\hline $\begin{array}{l}\text { A.5 (2002-2003) } \\
3.2 .1 .5(2004-2017)\end{array}$ & $\begin{array}{l}\text { Льготные взносы в строительно- } \\
\text { сберегательные кассы для лиц с } \\
\text { низкими доходами }\end{array}$ & & 710. Социальная защита (жилье) \\
\hline \begin{tabular}{|l|} 
A.6 (2002-2003) \\
3.2.1.6 (2004-2017) \\
\end{tabular} & Поддержка жертв войн & & $\begin{array}{l}\text { 710. Социальная защита (постра- } \\
\text { давшие) }\end{array}$ \\
\hline $\begin{array}{l}\text { A.7 (2002-2003) } \\
\text { 3.2.1.7 (2004-2017) }\end{array}$ & $\begin{array}{l}\text { Поддержка жертв военной/ аль- } \\
\text { тернативной гражданской служ- } \\
\text { бы, политических и нацистских } \\
\text { репрессий }\end{array}$ & & $\begin{array}{l}\text { 710. Социальная защита (постра- } \\
\text { давшие) }\end{array}$ \\
\hline $\begin{array}{l}\text { A.8 - часть }(2002-2003) \\
3.2 .1 .8 \text { - часть }(2004-2017)\end{array}$ & $\begin{array}{l}\text { Медицинское страхование сель- } \\
\text { ских хозяев (часть сельскохозяй- } \\
\text { ственной социальной политики) }\end{array}$ & & 707. Здравоохранение \\
\hline $\begin{array}{l}\text { А.8 - часть }(2002-2003) \\
3.2 .1 .8 \text { - часть }(2004-2017)\end{array}$ & $\begin{array}{l}\text { Страхование сельских хозяев от } \\
\text { несчастных случаев (часть сель- } \\
\text { скохозяйственной социальной } \\
\text { политики) }\end{array}$ & & $\begin{array}{l}\text { 710. Социальная защита (другие } \\
\text { вопросы соцзащиты) }\end{array}$ \\
\hline $\begin{array}{l}\text { А. } 8 \text { - часть }(2002-2003) \\
3.2 .1 .8 \text { - часть }(2004-2017)\end{array}$ & $\begin{array}{l}\text { Пенсионное обеспечение сель- } \\
\text { ских хозяев (часть сельскохозяй- } \\
\text { ственной социальной политики) }\end{array}$ & & 710. Социальная защита (пенсии) \\
\hline $\begin{array}{l}\text { A.9 (2002-2003) } \\
\text { 3.2.1.9(2004-2010) } \\
\text { 3.2.1.10/3.2.1.11(2011-2017) } \\
\end{array}$ & $\begin{array}{l}\text { Прочие мероприятия в социаль- } \\
\text { ной сфере }\end{array}$ & & $\begin{array}{l}\text { 710. Социальная защита (другие } \\
\text { вопросы соцзащиты) }\end{array}$ \\
\hline $3.2 .1 .9(2011-2017)$ & $\begin{array}{l}\text { Фонд обязательного медицинско- } \\
\text { го страхования }\end{array}$ & & 707. Здравоохранение \\
\hline \begin{tabular}{|l} 
B. $(2002-2003)$ \\
3.2.2 (2004-2017) \\
\end{tabular} & $\begin{array}{l}\text { Оборона (военная оборона, про- } \\
\text { чие задачи в сфере обороны) }\end{array}$ & & 702. Оборона \\
\hline $\begin{array}{l}\text { C. }(2002-2003) \\
\text { 3.2.3 (2004-2017) }\end{array}$ & $\begin{array}{l}\text { Сельское хозяйство, продовольст- } \\
\text { вие (совершенствование аграрной } \\
\text { структуры и защиты побережья, } \\
\text { прочее в сфере сельского/лесного } \\
\text { хозяйства) }\end{array}$ & & 704. Экономические вопросы \\
\hline $\begin{array}{l}\text { D. }(2002-2003) \\
\text { 3.2.4 (2004-2017) }\end{array}$ & $\begin{array}{l}\text { Стимулирование экономики } \\
\text { (энергетика, судо- и авиастроение } \\
\text { и экспорт, инновационный малый } \\
\text { и средний бизнес, экономика ре- } \\
\text { гионов, госгарантии и инфоком- } \\
\text { муникационные технологии) } \\
\end{array}$ & & 704. Экономические вопросы \\
\hline $\begin{array}{l}\text { E. }(2002-2003) \\
\text { 3.2.5 (2004-2017) }\end{array}$ & \begin{tabular}{|l|} 
Транспортная сеть (федеральные \\
железные дороги, федеральные \\
автомагистрали, федеральные \\
водные пути, местные автодоро- \\
ги, пр. в сфере транспортной сети)
\end{tabular} & & 704. Экономические вопросы \\
\hline
\end{tabular}

Научно-аналитический вестник ИЕ РАН, 2018, №6 


\begin{tabular}{|c|c|c|c|}
\hline \multicolumn{2}{|c|}{$\begin{array}{c}\text { Статьи функциональной классификации, применяемой в } \\
\text { федеральных финансовых планах Германии }\end{array}$} & \multirow[t]{2}{*}{\begin{tabular}{|c|} 
Направление \\
трансформации
\end{tabular}} & \multirow{2}{*}{\begin{tabular}{|l|}
\multicolumn{1}{|c|}{$\begin{array}{c}\text { Разделы функциональной } \\
\text { классификации МВФ }\end{array}$} \\
706. Жилищная и коммунальная \\
инфраструктура
\end{tabular}} \\
\hline \begin{tabular}{|l|} 
F. $(2002-2003)$ \\
3.2.6 (2004-2017)
\end{tabular} & $\begin{array}{l}\text { Строительство жилья и городской } \\
\text { инфраструктуры }\end{array}$ & & \\
\hline \multicolumn{2}{|c|}{$\begin{array}{l}\text { G. (2002-2003) } \\
\text { Наука, образование, культура } \\
\text { 3.2.7 (2004-2017) }\end{array}$} & & \\
\hline $\begin{array}{l}\text { G.1 (2002-2003) } \\
\text { 3.2.7.1 (2004-2017) }\end{array}$ & $\begin{array}{l}\text { Наука вне высших учебных заве- } \\
\text { дений }\end{array}$ & & $\begin{array}{l}\text { 709. Образование } \\
\text { и Наука }\end{array}$ \\
\hline $\begin{array}{l}\text { G.2 } 2002-2003) \\
3.2 .7 .2(2004-2017)\end{array}$ & Высшие учебные заведения & & $\begin{array}{l}\text { 709. Образование } \\
\text { и Наука }\end{array}$ \\
\hline $\begin{array}{l}\text { G.3 }(2002-2003) \\
3.2 .7 .3(2004-2017)\end{array}$ & $\begin{array}{l}\text { Стипендии, поддержка молодых } \\
\text { ученых }\end{array}$ & & $\begin{array}{l}\text { 709. Образование } \\
\text { и Наука }\end{array}$ \\
\hline $\begin{array}{l}\text { G.4 (2002-2003) } \\
\text { 3.2.7.4 (2004-2017) }\end{array}$ & $\begin{array}{l}\text { Профессиональное образование и } \\
\text { прочие направления образования }\end{array}$ & & $\begin{array}{c}\text { 709. Образование } \\
\text { и Наука }\end{array}$ \\
\hline $\begin{array}{l}\text { G.5 (2002-2003) } \\
\text { 3.2.7.5 (2004-2017) }\end{array}$ & Культура & $>$ & 708. Отдых, культура, религия \\
\hline $\begin{array}{l}\text { H. - часть }(2002-2003) \\
3.2 .8(2004-2017)\end{array}$ & Охрана окружающей среды & & 705. Охрана окружающей среды \\
\hline $\begin{array}{l}\text { Н. - часть }(2002-2003) \\
\text { 3.2.9 (2004-2017) }\end{array}$ & Спорт & & 708. Отдых, культура, религия \\
\hline $\begin{array}{l}\text { I. }(2002-2003) \\
\text { 3.2.10 (2004-2017) }\end{array}$ & $\begin{array}{l}\text { Внутренняя безопасность, имми- } \\
\text { грация }\end{array}$ & & $\begin{array}{l}\text { 703. Общественный порядок и } \\
\text { безопасность }\end{array}$ \\
\hline $\begin{array}{l}\text { J. }(2002-2003) \\
\text { 3.2.11 (2004-2017) }\end{array}$ & $\begin{array}{l}\text { Экономическая помощь разви- } \\
\text { вающимся странам }\end{array}$ & & $\begin{array}{l}\text { 701. Государственные службы } \\
\text { общего назначения }\end{array}$ \\
\hline \multicolumn{2}{|c|}{$\begin{array}{l}\text { К. (2002-2003) } \\
\text { Общие вопросы госфинансов } \\
\text { 3.2.12 (2004-2017) } \\
\end{array}$} & & \\
\hline \begin{tabular}{|l} 
K.1 (2002-2003) \\
3.2.12.1 (2004-2017) \\
\end{tabular} & $\begin{array}{l}\text { Проценты по государственному } \\
\text { долгу }\end{array}$ & & $\begin{array}{l}\text { 701. Государственные службы } \\
\text { общего назначения }\end{array}$ \\
\hline $\begin{array}{l}\text { K.2 (2002-2003) } \\
\text { 3.2.12.2(2004-2017) }\end{array}$ & $\begin{array}{l}\text { Пенсионное обеспечение госслу- } \\
\text { жащих, военных }\end{array}$ & & $\begin{array}{l}\text { 701. Государственные службы } \\
\text { общего назначения }\end{array}$ \\
\hline $\begin{array}{l}\text { K.3 (2002-2003) } \\
3.2 .12 .3(2004-2010) \\
3.2 .12 .5(2011) \\
3.2 .13(2012-2014) \\
3.2 .14(2015-2017) \\
\end{array}$ & Фонд особого имущества & & $\begin{array}{l}\text { 701. Государственные службы } \\
\text { общего назначения }\end{array}$ \\
\hline $\begin{array}{l}\text { K.4 (2002-2003) } \\
\text { 3.2.12.4 (2004-2010) } \\
3.2 .12 .3(2011-2017) \\
\end{array}$ & $\begin{array}{l}\text { Фонды-преемники фонда по } \\
\text { управлению госимуществом }\end{array}$ & & $\begin{array}{l}\text { 701. Государственные службы } \\
\text { общего назначения }\end{array}$ \\
\hline 3.2.12.4 (2011-2014) & $\begin{array}{l}\text { Фонд европейского стабилизаци- } \\
\text { онного механизма }\end{array}$ & & $\begin{array}{l}\text { 701. Государственные службы } \\
\text { общего назначения }\end{array}$ \\
\hline
\end{tabular}


Таблица2

Группировка статей функциональной классификации, применяемой в федеральных финансовых планах Германии, в разделы функциональной классификации МВФ

\begin{tabular}{|l|l|}
\hline Статьи функциональной классификации, применяемой в федеральных финансо- & Разделы функциональной клас-
\end{tabular} вых планах Германии, с кодами по функциональной классификации МВФ

70112. Государственные фонды, в т.ч.:

- фонды-преемники фонда по управлению госимуществом

- фонд европейского стабилизационного механизма

- фонд особого имущества

7012. Экономическая помощь развивающимся странам

7017. Проценты по государственному долгу

7021. Военная оборона

7025. Прочие задачи в сфере обороны

сификации МВФ

7031-7034, 7036. Внутренняя безопасность, иммиграция

7042. Сельское хозяйство, в т.ч.:

- совершенствование аграрной структуры и защиты побережья

- прочее в сфере сельского/лесного хозяйства

7043-7044, 7046-7047. Энергетика, добывающая и обрабатывающая промышленность,

строительство, связь, прочие отрасли, в т.ч.:

- энергетика

- судо- и авиастроение и экспорт

- инновационный малый и средний бизнес

- экономика регионов

- госгарантии и инфокоммуникационные технологии

7045. Транспортная сеть, в т.ч.:

- федеральные железные дороги

- федеральные автомагистрали

- федеральные водные пути

- местные автодороги и - прочее в сфере транспортной сети

705. Охрана окружающей среды

7061. Жилищное строительство

7062. Строительство городской инфраструктуры

707. Здравоохранение, обеспечиваемое путем медицинского страхования, в т.ч.:

- медицинское страхование сельских хозяев (часть сельскохозяйственной социальной политики)

- Фонд обязательного медицинского страхования

7081. Спорт

7082. Культура

70941-70942. Высшие учебные заведения, стипендии, поддержка молодых учёных

7095. Профессиональное образование и прочие направления образования

Наука вне высших учебных заведений

7102. Старость, в т.ч.:

- Федеральный фонд обязательного пенсионного страхования

- пенсионное обеспечение сельских хозяев (часть сельскохозяйственной социальной политики)

- пенсионное обеспечение госслужащих, военных

7103. Пострадавшие, в т.ч.:

- поддержка жертв войн

- поддержка жертв военной/альтернативной гражданской службы, политических и нацистских репрессий

7104. Семья и дети (поддержка родителей и детей)

7105. Безработица, в т.ч.:

- содействие трудоустройству

- базовое обеспечение безработных

7106. Жилье, в т.ч.:

- льготная аренда жилья для малоимущих

- льготные взносы в строительно-сберегательные кассы для лиц с низкими доходами

7109. Другие вопросы соцзащиты, в т.ч.:

- страхование сельских хозяев от несчастных случаев (часть сельскохозяйственной социальной политики) и - прочие мероприятия в социальной сфере

701. Государственные службы общего назначения

02. Оборона

703. Общественный порядок и безопасность

704. Экономические вопросы

705. Охрана окружающее среды

706. Жилищная и коммунальная инфраструктура

707. Здравоохранение

08. Отдых, культура, религия

709. Образование и Наука

710. Социальная защита

\section{Научно-аналитический вестник ИЕ РАН, 2018, №6}


Совокупные расходы федерального бюджета (ФБ) Германии по функциональной классификации (ФК) Международного валютного фонда

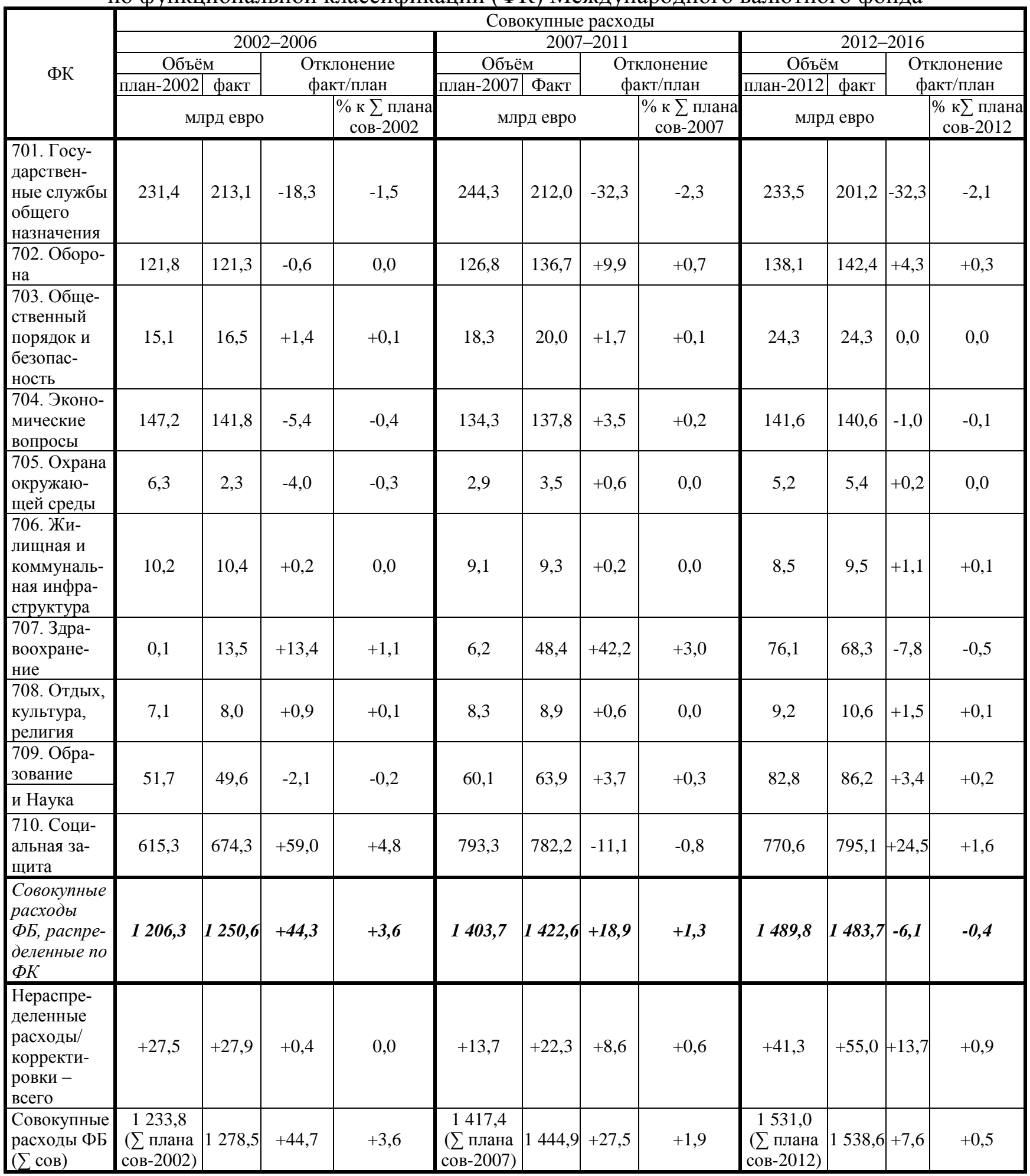


Таблица 4

Совокупные расходы федерального бюджета (ФБ) Германии по экономической классификации (ЭК), применяемой в федеральных финансовых пятилетних планах Германии

\begin{tabular}{|c|c|c|c|c|c|c|c|c|c|c|c|c|}
\hline \multirow{5}{*}{ ЭК } & \multicolumn{12}{|c|}{ Совокупные расходы } \\
\hline & \multicolumn{4}{|c|}{$2002-2006$} & \multicolumn{4}{|c|}{$2007-2011$} & \multicolumn{4}{|c|}{$2012-2016$} \\
\hline & \multicolumn{2}{|c|}{ Объём } & \multirow{2}{*}{\multicolumn{2}{|c|}{$\begin{array}{c}\text { Отклонение } \\
\text { факт/план }\end{array}$}} & \multicolumn{2}{|c|}{ Объём } & \multirow{2}{*}{\multicolumn{2}{|c|}{$\begin{array}{c}\text { Отклонение } \\
\text { факт/план }\end{array}$}} & \multicolumn{2}{|c|}{ Объём } & \multirow{2}{*}{\multicolumn{2}{|c|}{$\begin{array}{c}\text { Отклонение } \\
\text { факт/план }\end{array}$}} \\
\hline & план-2002 & факт & & & план-2007 & Факт & & & план-2012 & факт & & \\
\hline & \multicolumn{3}{|c|}{ млрд евро } & $\begin{array}{c}\% \text { к } \sum \text { планана } \\
\text { сов-2002 } \\
\end{array}$ & \multicolumn{3}{|c|}{ млрд евро } & $\begin{array}{c}\% \text { к } \sum \text { плана } \\
\text { сов-2007 }\end{array}$ & \multicolumn{3}{|c|}{ млрд евро } & $\begin{array}{c}\% \text { к } \sum \text { плана } \\
\text { сов-2012 }\end{array}$ \\
\hline $\begin{array}{l}\text { 1. Текущие } \\
\text { pacходы, в т.ч. }\end{array}$ & 1115,5 & 1159,8 & $+44,3$ & $+3,6$ & 1295,6 & 1315,8 & $+20,2$ & $+1,4$ & 1386,3 & 1355,0 & $-31,3$ & $-2,0$ \\
\hline $\begin{array}{l}\text { 1.1. Расходы на } \\
\text { персонал орга- } \\
\text { низаций секто- } \\
\text { ра госуправле- } \\
\text { ния и воору- } \\
\text { жённых сил, } \\
\text { вкл. выплаты } \\
\text { пенсионерам }\end{array}$ & 136,2 & 133,5 & $-2,7$ & $-0,2$ & 133,7 & 137,0 & $+3,3$ & $+0,2$ & 142,5 & 146,4 & $+3,9$ & $+0,3$ \\
\hline $\begin{array}{l}\text { 1.2. Госзакуп- } \\
\text { ки товаров и } \\
\text { услуг }\end{array}$ & 82,5 & 87,1 & $+4,6$ & $+0,4$ & 98,9 & 103,1 & $+4,2$ & $+0,3$ & 121,5 & 120,5 & $-1,0$ & $-0,1$ \\
\hline $\begin{array}{l}\text { 1.3. Проценты } \\
\text { по госдолгу }\end{array}$ & 201,9 & 185,3 & $-16,6$ & $-1,3$ & 214,8 & 183,1 & $-31,7$ & $-2,2$ & 179,0 & 126,2 & $\mid-52,8$ & $-3,4$ \\
\hline $\begin{array}{l}\text { 1.4. Текущие } \\
\text { субсидии/дот- } \\
\text { ации и переда- } \\
\text { ча имущества } \\
\text { для неинвести- } \\
\text { ционных целей }\end{array}$ & 694,9 & 753,9 & $+59,0$ & $+4,8$ & 848,2 & 892,6 & $+44,4$ & $+3,1$ & 943,3 & 961,9 & $+18,6$ & $+1,2$ \\
\hline $\begin{array}{l}\text { 2. Капиталь- } \\
\text { ные расходы, в } \\
\text { г.ч. }\end{array}$ & 129,2 & 118,7 & $-10,5$ & $-0,9$ & 121,9 & 129,1 & $+7,2$ & $+0,5$ & 149,7 & 165,0 & $+15,3$ & $+1,0$ \\
\hline $\begin{array}{l}\text { 2.1. Инвести- } \\
\text { ции в матери- } \\
\text { альные активы }\end{array}$ & 36,3 & 34,6 & $-1,7$ & $-0,1$ & 34,4 & 37,5 & $+3,1$ & $+0,2$ & 37,2 & 40,1 & $+2,9$ & $+0,2$ \\
\hline $\begin{array}{l}\text { 2.2. Инвести- } \\
\text { ционные суб- } \\
\text { сидии/дотации }\end{array}$ & 71,3 & 67,9 & $-3,4$ & $-0,3$ & 68,6 & 75,3 & $+6,7$ & $+0,5$ & 73,9 & 92,7 & $+18,8$ & $+1,2$ \\
\hline $\begin{array}{l}\text { 2.3. Ссуды и } \\
\text { долевые вло- } \\
\text { жения }\end{array}$ & 21,6 & 16,2 & $-5,4$ & $-0,4$ & 18,9 & 16,3 & $-2,6$ & $-0,2$ & 38,6 & 32,2 & $-6,4$ & $-0,4$ \\
\hline $\begin{array}{l}\text { Совокупные } \\
\text { расходы ФБ, } \\
\text { распределен- } \\
\text { ные по ЭК }\end{array}$ & 1244,7 & 1278,5 & $+33,8$ & $+2,7$ & 1417,5 & 1444,9 & $+27,4$ & $+1,9$ & 1536,0 & 1520,0 & $-16,0$ & $-1,0$ \\
\hline $\begin{array}{l}\text { Нераспреде- } \\
\text { пенные по ЭК } \\
\text { расходы/кор- } \\
\text { ректировки }\end{array}$ & $-10,9$ & & $+10,9$ & $+0,9$ & $-0,1$ & & $+0,1$ & 0,0 & $-5,0$ & $+18,6$ & $+23,6$ & $+1,5$ \\
\hline $\begin{array}{l}\text { Совокупные } \\
\text { расходы ФБ }(\Sigma \\
\text { сов) }\end{array}$ & \begin{tabular}{|c|}
1233,8 \\
$\left(\sum\right.$ плана \\
сов-2002) \\
\end{tabular} & 1278,5 & $+44,7$ & $+3,6$ & \begin{tabular}{|c|}
1417,4 \\
$\left(\sum\right.$ плана \\
сов-2007) \\
\end{tabular} & 1444,9 & $+27,5$ & $+1,9$ & \begin{tabular}{|c|}
1531,0 \\
$\left(\sum\right.$ плана \\
сов-2012) \\
\end{tabular} & 1538,6 & $+7,6$ & $+0,5$ \\
\hline
\end{tabular}


Таблица 5

Текущие расходы федерального бюджета (ФБ) Германии по функциональной классификации (ФК)

Международного валютного фонда

\begin{tabular}{|c|c|c|c|c|c|c|c|c|c|c|c|c|}
\hline \multirow{6}{*}{\begin{tabular}{|l|}
\multicolumn{1}{|c|}{ ФК } \\
\\
701. Государ- \\
ственные слу- \\
жбы общего \\
назначения \\
\end{tabular}} & \multicolumn{12}{|c|}{ Текущие расходы } \\
\hline & \multicolumn{4}{|c|}{ 2002-2006 } & \multicolumn{4}{|c|}{$2007-2011$} & \multicolumn{4}{|c|}{$2012-2016$} \\
\hline & \multirow{2}{*}{\multicolumn{2}{|c|}{\begin{tabular}{|c|c|}
\multicolumn{2}{|c|}{ Объём } \\
план-2002 факт
\end{tabular}}} & \multirow{2}{*}{\multicolumn{2}{|c|}{$\begin{array}{c}\text { Отклонение } \\
\text { факт/план }\end{array}$}} & \multicolumn{2}{|c|}{ Объём } & \multirow{2}{*}{\multicolumn{2}{|c|}{$\begin{array}{c}\text { Отклонение } \\
\text { факт/план }\end{array}$}} & \multicolumn{2}{|c|}{ Объём } & \multirow{2}{*}{\multicolumn{2}{|c|}{$\begin{array}{c}\text { Отклонение } \\
\text { факт/план }\end{array}$}} \\
\hline & & & & & план-2007 & Факт & & & план-2012 & факт & & \\
\hline & \multicolumn{3}{|c|}{ млрд евро } & $\left|\begin{array}{c}\% \text { к } \sum \text { плана } \\
\text { тек-2002 }\end{array}\right|$ & \multicolumn{3}{|c|}{ млрд евро } & $\begin{array}{c}\% \text { к } \sum \text { плана } \\
\text { тек-2007 }\end{array}$ & \multicolumn{3}{|c|}{ млрд евро } & $\begin{array}{c}\% \text { к } \sum \text { плана } \\
\text { тек-2012 }\end{array}$ \\
\hline & 216,7 & 198,6 & $-18,1$ & $-1,6$ & 224,8 & 190,5 & $-34,3$ & $-2,6$ & 190,7 & 157,3 & $-33,4$ & $-2,4$ \\
\hline & 120,3 & 119,5 & $-0,9$ & $-0,1$ & 125,2 & 135,4 & $+10,2$ & $+0,8$ & 137,1 & 140,9 & $+3,8$ & $+0,3$ \\
\hline $\begin{array}{l}703 . \text { Общест- } \\
\text { венный поря- } \\
\text { док и безопас- } \\
\text { ность }\end{array}$ & 13,7 & 15,2 & $+1,5$ & $+0,1$ & 16,7 & 18,4 & $+1,7$ & $+0,1$ & 22,8 & 22,8 & $+0,0$ & 0,0 \\
\hline $\begin{array}{l}\text { 704. Экономи- } \\
\text { ческие вопросы }\end{array}$ & 70,7 & 73,4 & $+2,7$ & $+0,2$ & 74,6 & 68,8 & $-5,8$ & $-0,4$ & 71,2 & 70,5 & $-0,7$ & 0,0 \\
\hline $\begin{array}{l}\text { 705. Охрана } \\
\text { окружающей } \\
\text { среды }\end{array}$ & 5,3 & 1,3 & $-4,0$ & $-0,4$ & 1,5 & 1,5 & 0,0 & 0,0 & 1,7 & 1,7 & 0,0 & 0,0 \\
\hline $\begin{array}{l}\text { 706. Жилищная } \\
\text { и коммуналь- } \\
\text { ная инфра- } \\
\text { структура }\end{array}$ & 2,6 & 2,9 & $+0,3$ & 0,0 & 3,3 & 1,2 & $-2,1$ & $-0,2$ & 1,1 & 2,0 & $+1,0$ & $+0,1$ \\
\hline $\begin{array}{l}707 . \text { Здраво- } \\
\text { охранение }\end{array}$ & 0,1 & 13,5 & $+13,4$ & $+1,2$ & 4,7 & 48,4 & $+43,7$ & $+3,4$ & 76,1 & 68,3 & $-7,8$ & $-0,6$ \\
\hline $\begin{array}{l}\text { 708. Отдых, } \\
\text { культура, рели- } \\
\text { гия }\end{array}$ & 6,1 & 7,0 & $+0,9$ & $+0,1$ & 7,3 & 7,5 & $+0,2$ & 0,0 & 8,4 & 9,5 & $+1,2$ & $+0,1$ \\
\hline $\begin{array}{l}\text { 709. Образова- } \\
\text { ние }\end{array}$ & 35,9 & 36,4 & $+0,5$ & 0,0 & 47,2 & 49,2 & $+1,9$ & $+0,1$ & 72,6 & 71,5 & $-1,1 \mid$ & $-0,1$ \\
\hline и Наука & & & & & & & & & & & & \\
\hline $\begin{array}{l}\text { 710. Социаль- } \\
\text { ная защита }\end{array}$ & 615,3 & 673,4 & $+58,1$ & $+5,4$ & 793,3 & 782,2 & $-11,1$ & $-0,9$ & 770,6 & 794,9 & $+24,3$ & $+1,8$ \\
\hline $\begin{array}{l}\text { Текушие расхо- } \\
\text { ды ФБ, распре- } \\
\text { деленные по } \\
\Phi К\end{array}$ & 1086,8 & 1141,0 & $+54,2$ & $+5,0$ & 1298,7 & 1303,0 & $+4,3$ & $+0,3$ & 1352,2 & 1339,5 & $-12,7$ & $-0,9$ \\
\hline $\begin{array}{l}\text { Нераспреде- } \\
\text { пенные по ФК } \\
\text { расходы/ кор- } \\
\text { ректировки } \\
\end{array}$ & $+28,7$ & $+18,8$ & $-9,9$ & $-0,9$ & $-3,1$ & $+12,8$ & $+15,9$ & $+1,2$ & $+34,1$ & $+15,5$ & $-18,6$ & $-1,3$ \\
\hline $\begin{array}{l}\text { Текущие рас- } \\
\text { ходы ФБ ( }( \\
\text { тек) }\end{array}$ & $\begin{array}{c}1115,5 \\
\left(\sum \text { плана }\right. \\
\text { тек-2002) }\end{array}$ & $\mid$\begin{tabular}{ll|}
1 & 159,8
\end{tabular} & $+44,3$ & $+4,0$ & $\begin{array}{c}1295,6 \\
\left(\sum \text { плана }\right. \\
\text { тек-2007) }\end{array}$ & 1315,8 & $+20,2$ & $+1,6$ & \begin{tabular}{|c|}
1386,3 \\
$\left(\sum\right.$ плана \\
тек-2012) \\
\end{tabular} & 1355,0 & $\mid-31,3$ & $-2,3$ \\
\hline
\end{tabular}


Капитальные расходы федерального бюджета (ФБ) Германии по функциональной классификации (ФК)

Международного валютного фонда

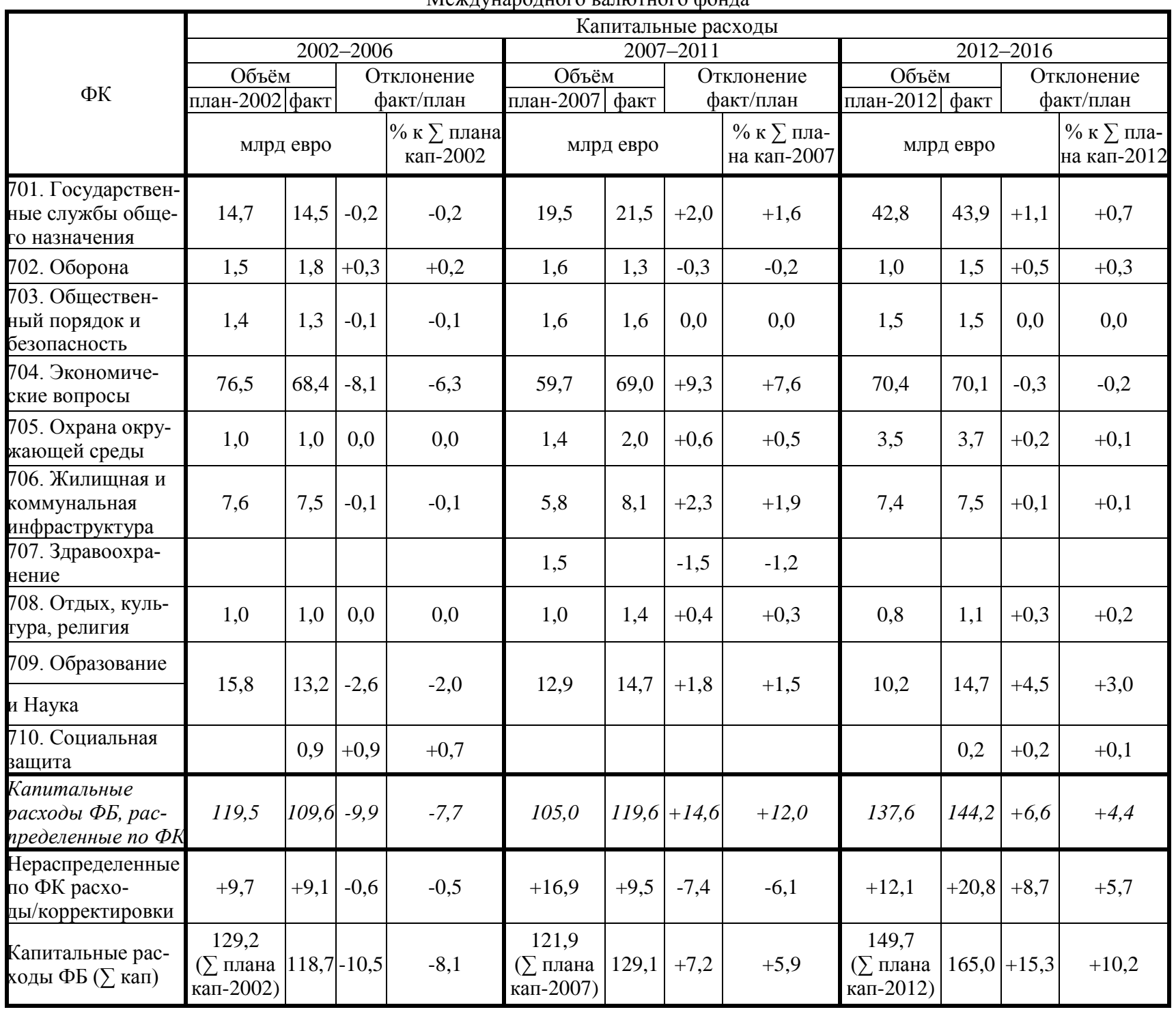

